\title{
Coronary calcification in patients with end-stage renal disease: a novel endocrine disorder?
}

\author{
Georgios Efstratiadis ${ }^{1}$, Konstantinos Koskinas² ${ }^{2}$ Efstathios Pagourelias ${ }^{2}$ \\ ${ }^{1}$ Nephrology Department of Aristotle University, ${ }^{2}$ B Propaedeftiki Internal Medicine Department Aristotle University, \\ Thessaloniki, Greece
}

\begin{abstract}
Cardiovascular mortality is significantly increased among patients with end-stage renal disease. The commonly observed vascular calcification in such patients has been considered as one of the causative factors. In patients undergoing dialysis, the incidence of coronary artery calcification is 2-5 times higher compared to patients with normal renal function and angiographically demonstrated coronary artery disease. Moreover, epidemiological studies have revealed a significant correlation of the extent of coronary artery calcification with the severity of underlying atherosclerotic lesions. Vascular calcification was initially considered as a passive process of hydroxyapatite deposition due to elevated plasma concentrations of calcium and phosphate. Nevertheless, there is a growing body of evidence that vascular calcification is an actively regulated and cell-mediated process. This phenomenon includes phenotypic alterations of vascular smooth muscle cells mainly resulting from an imbalance between promoters (such as increased Ca $x P$ product) and inhibitors (fetuin-A, GLA protein, osteoprotegerin) of mineral deposition. With regard to the therapeutic approach, despite the evident effectiveness of both traditional and innovative remedies in the management of metabolic and electrolytic abnormalities of patients with end-stage renal disease, an individualized intervention based on etiopathogenesis is really required.
\end{abstract}

Key words: Atherosclerosis, Calcification, Calcification inhibitors, Fetuin-A, Haemodialysis, Matrix Cla protein, Osteoprotegerin, PTH, Renal failure

\section{INTRODUCTION}

Vascular calcification is often observed in advanced atherosclerotic lesions in the general population and constitutes a process related to ageing. However, the

Address for correspondence:

Efstratiadis Georgios, Department of Nephrology, Aristotle University, 14 Ethnikis Amynis str, Thessaloniki 546 21, Greece, Tel.: 6974 799768, e-mail: efstrati@med.auth.gr Received 10-01-07, Revised 25-02-07, Accepted 10-03-07 fact that it is a common complication in patients with end-stage renal disease (ESRD), contributing to the high mortality affecting this population, has raised intense interest concerning the pathogenesis, clinical implications and more appropriate therapeutic management of this disorder.

Extraosseous calcification is an almost inevitable process in patients with ESRD. It can lead to a variety of complications, including calcification of soft tis- 
sues and solid organs and an entity known as calcific uraemic arterioliopathy or calciphylaxis. ${ }^{1}$ However, the calcification of blood vessels and of cardiac valves is the most common and clinically intriguing manifestation.

It has been reported that patients under haemodialysis have a 2- to 5-fold increase in coronary artery calcification compared to age-matched patients with normal renal function and angiographically proven coronary artery disease. ${ }^{1}$ It has also been found that there is a positive correlation of the extent of coronary artery calcification and the instability of atheromatous plaques with the increased risk for myocardial infarction. ${ }^{2}$

Vascular calcification has arisen scientific interest since the early days of haemodialysis. A radiological skeletal survey examination carried out in 1976 in patients with severe renal disease revealed an incidence of $30 \%$ in the age group of $15-30$ years and over $50 \%$ in the age group of 40-50 years. ${ }^{3}$ Autopsy findings in 1969 and 1977 also demonstrated extensive soft tissue and vascular calcification in $50-80 \%$ of patients under haemodialysis. ${ }^{4,5}$

\section{CARDIOVASCULAR DISEASE IN PATIENTS WITH CHRONIC RENAL DISEASE}

Worldwide registry data clearly demonstrate that cardiovascular disease is the leading cause of mortality among patients with renal failure treated with haemodialysis, with an estimated 10-30 times higher mortality compared to that of the general population after adjustment for sex, age and the presence of diabetes mellitus. ${ }^{6,7}$ Furthermore, there is a linear correlation between the severity of cardiovascular disease and the stage of chronic kidney disease. ${ }^{8,9}$ Additionally, cardiovascular mortality is $2-5$ times higher in kidney transplantation patients compared to the general population. ${ }^{6}$ It is estimated that allcause annual mortality ranges between $12 \%$ and $25 \%$, while approximately $50 \%$ of this excess mortality is due to cardiovascular causes. ${ }^{10}$ This is attributed to the combination of several factors, including:

1. the high prevalence of atherosclerosis, heart failure and left ventricular hypertrophy in haemodialysis patients, ${ }^{11,12}$ and
2. the poor prognosis with high mortality rate after myocardial infarction or heart failure. ${ }^{8,9,13}$

The high prevalence of cardiovascular disease among patients with ESRD has been associated with high incidence of Framingham risk factors in the specific population. ${ }^{14-17}$ However, it has been shown that the estimation of cardiovascular risk based exclusively on Framingham risk factors is inadequate to explain the high incidence of cardiovascular events in patients with chronic kidney disease, implying the presence of additional risk factors. ${ }^{14-19}$ Arterial calcification and especially extensive medial calcification have been implicated as potential causative factors of the increased mortality in patients with renal insufficiency. ${ }^{20}$ Since traditionally established risk factors, including hypertension, dyslipidaemia and cigarette smoking, fail to explain the significantly high mortality, interest has focused on the unique combination of risk factors related to chronic uraemia. Advanced vascular calcification may represent a uraemia specific phenomenon directly affecting cardiovascular function. London et $\mathrm{al}^{21}$ were the first investigators who established the relation between the extent of vascular calcification and decreased survival.

Arterial disease and left ventricular hypertrophy $(\mathrm{LVH})^{22}$ are considered the two major risk factors responsible for the high rate of cardiovascular mortality in haemodialysis patients. The term "arterial disease" refers not only to the presence of atherosclerosis, an established cause of cardiovascular disease, but also to vascular alterations described by the term arteriosclerosis, which contribute to vascular remodelling and result in the stiffening of the arterial wall, with significant haemodynamic and clinical consequences in ESRD patients. Arterial disease observed in ESRD patients is characterized by extensive intimal as well as medial calcification. The latter has been shown to affect vascular elasticity ${ }^{23}$ and leads to increased arterial wall stiffness of large capacity, elastic-type arteries like the aorta and the common carotid artery, ${ }^{24}$ increased pulse pressure and decreased perfusion of coronary arteries during diastole. ${ }^{25}$ The presence and extent of vascular calcifications was shown to be independently predictive of subsequent cardiovascular and all-cause morbidity and mortality ${ }^{26,27}$ as well as of silent myocardial ischaemia. ${ }^{28} \mathrm{It}$ is therefore obvious that the haemodynamic and functional changes asso- 
ciated with calcification of the vasculature in general and of the coronary artery tree in particular have significant clinical consequences affecting morbidity and mortality in dialysis patients.

\section{CORONARY ARTERY CALCIFICATION IN PATIENTS WITH END-STAGE RENAL DISEASE}

Coronary calcium is a sensitive marker of underlying atherosclerotic disease ${ }^{29,30}$ and coronary calcification is positively correlated with atherosclerotic plaque burden, both calcified and non-calcified, ${ }^{31}$ increased risk of myocardial infarction ${ }^{32}$ and of cardiovascular events in individuals with normal renal function. ${ }^{33}$ Assessment of coronary calcium constitutes a remarkably accurate and sensitive method for the early detection of coronary atherosclerosis, ${ }^{34}$ since it enables detection of atherosclerotic lesions long before they become haemodynamically significant. ${ }^{35}$ The coronary artery calcium score has been used for risk stratification in patients with known or suspected coronary artery disease (CAD) $)^{36}$ and, according to published guidelines, it can help in identifying asymptomatic patients at low-to-intermediate risk, who may benefit from more aggressive risk factor modification. ${ }^{37}$

Coronary artery calcification is a common finding in patients undergoing haemodialysis (Figure 1). Depending on patients' age, some degree of coronary artery calcification is observed in $54 \%$ to $100 \%$ (mean $83 \%$ ) of dialysis patients, with scores significantly increased compared to the general population. ${ }^{38}$ A study by Goodman et al of young haemodialysis patients (aged 20 to 30 years) revealed that coronary artery calcification was present in a great proportion of patients and was related to the presence of hyperphosphataemia, increased $\mathrm{Ca} \times \mathrm{P}$ product and increased calcium ingestion. ${ }^{39}$ Another study in patients aged 19-39 years showed significant coronary artery calcification in more than $90 \%$ of patients undergoing haemodialysis. ${ }^{40}$ The coronary artery calcification incidence among patients undergoing haemodialysis, detected by means of electron beam computerized tomography (EBCT), exceeded 2 to 5 times the incidence observed in patients with angiographically proven coronary artery disease but normal renal function..$^{41}$ Once coronary artery calcification is

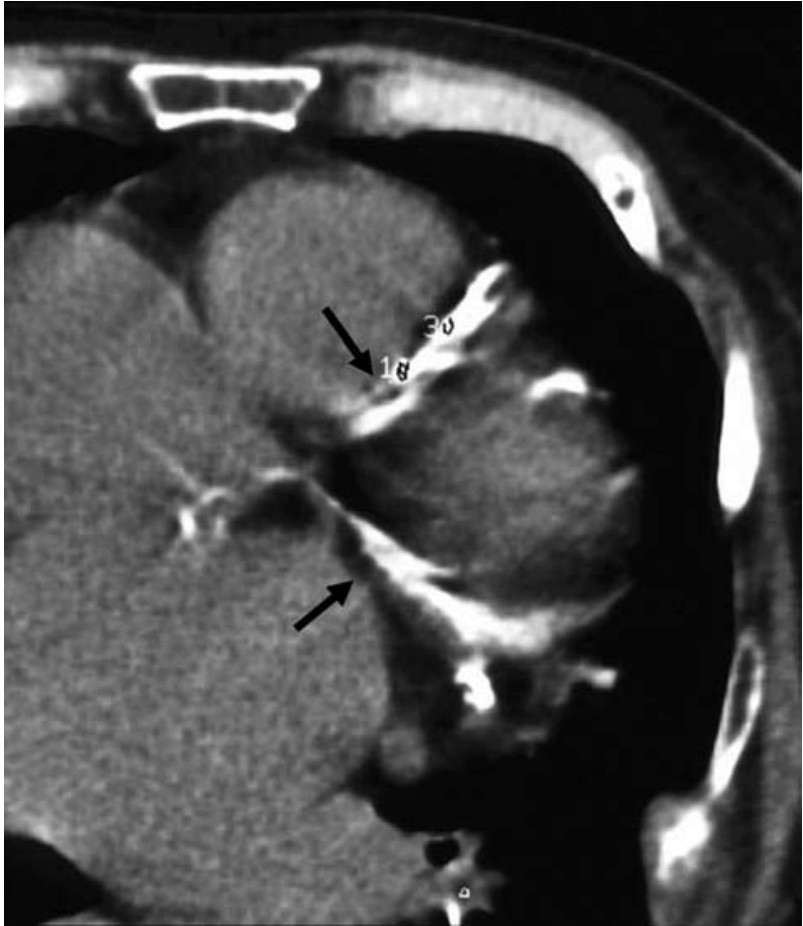

Figure 1. CT of a patient with chronic renal failure under haemodialysis. Coronary calcifications are demonstrated by arrows.

present in dialysis patients, it is progressive in nearly all studies ${ }^{39,41,42}$ with minimal or no progression after renal transplantation. ${ }^{43}$

\section{LOCATION - MORPHOLOGY}

The location as well as the morphology of calcium deposits in blood vessels are variable. Vascular calcification in end-stage renal disease can independently affect separate components of the vascular wall, that is, the intima and the media.

Anatomically, four discrete types of vascular calcium deposition can be observed: atherosclerotic/fibrotic calcification, cardiac valve calcification, medial artery calcification and vascular calciphylaxis. The latter process appears as amorphous calcium phosphate deposition and widespread organ and soft tissue involvement without osteogenesis or chondrogenesis. $^{44}$

In atherosclerotic lesions, calcification is mainly found in the intima ${ }^{45}$ in a dispersed punctuate form during the early stage of the disease and, as the process progresses, the aggregates of calcium phosphate 
crystals deposit to produce larger crystals associated with the necrotic regions of atheromas. ${ }^{46}$ In fact, calcification of the intima as a result of calcium deposition along with lipoproteins and/or cellular lipid debris seems to be an evolutionary step of the fibro-fatty plaque. In the setting of the calcified asymmetric atheromatous plaque, the initial dystrophic calcification process evolves to cartilage metaplasia as well as endochondral bone formation mainly induced by bone morphogenetic protein-2 (BMP2). BMP2, which can drive both osteogenic and chondrogenic differentiation from mesenchymal progenitors, is expressed in a myofibroblast cell population. The oxidative stress of microvascular endothelial cells also upregulates BMP2. ${ }^{44}$

On the other hand, calcification of the media, known as Mönckeberg's sclerosis, affects muscular type arteries and is characterized by non-inflammatory calcification of the media. Additionally, matrix vesicles can be seen in the medial artery wall, while osteogenesis resembles intramembranous (non-endochondral) bone formation. No cartilage formation is observed. ${ }^{44}$ Mediasclerosis is generally asymptomatic; it may however result in reduction of vascular elasticity, thereby causing an increase of systolic blood pressure (pseudohypertension), left ventricular hypertrophy and impaired coronary blood supply. ${ }^{47}$ Calcification of the media often occurs in lower limb arteries during ageing, but it is substantially more prominent in diabetic and uraemic patients. ${ }^{48}$ In uraemic patients calcification of the media is the predominant histological form, at least among younger patients. ${ }^{49}$ However, considering that chronic uraemia constitutes an atherogenic environment, ${ }^{50,51}$ a mixture of these two types of calcification often occurs.

\section{DETECTION AND QUANTIFICATION OF CORONARY ARTERY CALCIFICATION}

Electron beam computed tomography (EBCT) and multi-detector computer tomography (MDCT) currently represent the most commonly used modalities for the assessment of coronary artery calcification. EBCT is considered the gold standard for this purpose $^{52}$ and it has been used in the majority of studies concerning cardiac calcification in uraemic patients. Limitations for the widespread application of EBCT include the relatively high cost and limited access to this technique as opposed to the recently introduced application of the more widely available MDCT. Recent studies have shown excellent correlation between EBCT and MDCT..$^{53}$ Three different methods for calcium quantification and scoring are used: the most commonly applied Agatston method (a semi-quantitative method calculated as the product of the area of the plaque and a density coefficient), the volumetric method and the mass method, the latter exhibiting the best reproducibility. Other modalities less commonly applied include magnetic resonance imaging (MRI), echocardiography and optical coherence tomography.

\section{PATHOGENESIS}

Pathogenesis of vascular calcification in ESRD patients is not fully understood and is believed to be multifactorial. Numerous studies have revealed associations between vascular calcification and traditional as well as uraemia-specific risk factors, without necessarily proving a cause-effect relationship. Risk factors related to uraemia are depicted in Table 1.

Duration of haemodialysis is the risk factor with the strongest causative relation to vascular calcification. Furthermore, numerous studies have shown correlation of vascular calcification with the presence of hypercalcaemia, hyperphosphataemia, hyperparathyroidism, increased Ca x P product and/or use of calcium containing phosphate binders. ${ }^{1,39,40,54}$ However, these findings are not supported by other studies. ${ }^{41,55}$ The discrepancy could be attributed to methodological differences, especially concerning the sample size of each study, as well as the difficulty of associating a long-term complication, such as the calcification of the vascular wall, with rapidly changing parameters like the plasma concentration of calcium among dialysis patients. ${ }^{45}$ Discrepancy is also found regarding the correlation of vascular calcification with the levels of intact parathormone (i-PTH), since it is positive in some ${ }^{40,54}$ but not in other surveys. ${ }^{41,55}$ These findings also reflect our poor understanding of the pathophysiological role of parathormone in the process of vascular calcification, considering that cases of the most extensive form of extraosseous calcification, i.e. calciphylaxis, have been reported in patients without 
Table 1. Risk factors related (+) or not related (-) to vascular calcification in patients undergoing haemodialysis.

\begin{tabular}{|c|c|c|}
\hline \multirow[t]{2}{*}{ Risk factor } & \multicolumn{2}{|c|}{$\begin{array}{c}\text { Studies indicating correlation }(+) \text { or no correlation }(-) \\
\text { to vascular calcification* }\end{array}$} \\
\hline & $(+)$ & $(-)$ \\
\hline Hyperphosphataemia and Hypercalcaemia & $1,39,40,54$ & 41,55 \\
\hline Use of calcium-based phosphate binders & 39,55 & \\
\hline iPTH & 40,54 & $39,41,55$ \\
\hline Duration of haemodialysis or uraemia & $1,39,40,55,57,58$ & 41 \\
\hline Diabetes melitus & $1,54,59$ & \\
\hline Age & $1,41,55,39,54,57-59$ & \\
\hline Decreased fetuin-A serum levels & 60,61 & \\
\hline Dyslipidaemia and/or increased oxidized LDL & 59,62 & \\
\hline Increased CRP levels and/or presence of other inflammation markers & $40,54,55,57,58$ & 1,54 \\
\hline Hyperhomocysteinaemia & $40,58,59$ & \\
\hline
\end{tabular}

*: Modified table from: Floege J, Ketteler M. ${ }^{45}$ Numbers indicate the corresponding references.

secondary hyperparathyroidism. ${ }^{56}$

Other risk factors that have been associated with the development of vascular calcifications based on epidemiological studies and clinical trials include patients' age ${ }^{54,55,57-59}$ dyslipidaemia,${ }^{59,62}$ decreased serum levels of the calcification inhibitor fetuin$\mathrm{A}^{60,61}$ and diabetes mellitus, ${ }^{1,54,59}$ the latter being a fairly predictable correlation, since media sclerosis is typically present in the diabetic vasculature, even under non-uraemic conditions.

For many years, calcification of the vascular wall was considered to be the result of passive hydroxyapatite crystal precipitation, due to elevated blood calcium and phosphate concentrations. However, more recent data support the concept of a controlled process, resembling that of bone mineralization. It seems that vascular calcification includes alterations of vascular smooth muscle cells (SMC) and the expression of proteins normally involved in bone metabolism. Experimental work in knock-out animal models clearly indicates that the selective deletion of genes, such as matrix GLA protein ${ }^{63}$ osteoprotegerin ${ }^{64}$ and others, induces vascular calcification. The detection of bone-associated proteins in calcified regions of both coronary and peripheral arteries ${ }^{11}$ supports the above-mentioned theory. Furthermore, it has been reported that both bovine and human vascular smooth muscle cells are capable of mineralization in vitro ${ }^{65,66}$ in an osteoblast-like manner. These data imply that arterial calcification of both the intima and the media constitutes a regulated process resembling osteogenesis in many aspects. Moreover, it should be underlined that many of the factors associated with cardiovascular risk and/or vascular calcification in dialysis patients, including high levels of phosphate, ${ }^{67}$ calcitriol, ${ }^{68}$ urea,${ }^{69}$ lipoproteins, ${ }^{70,71}$ homocysteine, ${ }^{72}$ parathormone, and parathormone-related peptide ${ }^{73}$ promote mineralization of cultured vascular smooth muscle cells. The active, cell-mediated process of vascular calcification in dialysis patients resembles osteogenic differentiation, which is further confirmed by a series of ex vivo experiments. ${ }^{49,56}$ The expression of bone matrix protein osteopontin, bone sialoprotein, type I collagen and alkaline phosphatase was demonstrated in pathological specimens of calcified arteries and was characteristically absent in non-calcified specimens.

Vascular calcification is a multi-step process (Figure 2). ${ }^{2}$ The initial step is the differentiation of vascular cells of mesenchymal origin to osteoblast-like cells in atherosclerotic regions. Osteoblastic differentiation can potentially occur in several cell types, including smooth muscle cells, myofibroblasts and microvascular pericytes which exhibit alterations as an adjustment to several conditions, i.e. ageing, atherosclerosis, diabetes mellitus and chronic kidney disease. These alterations include loss of SMC markers and the development of osteoblastic features, such as expression of osteopontin, osteocalcin and alkaline phosphatase. 


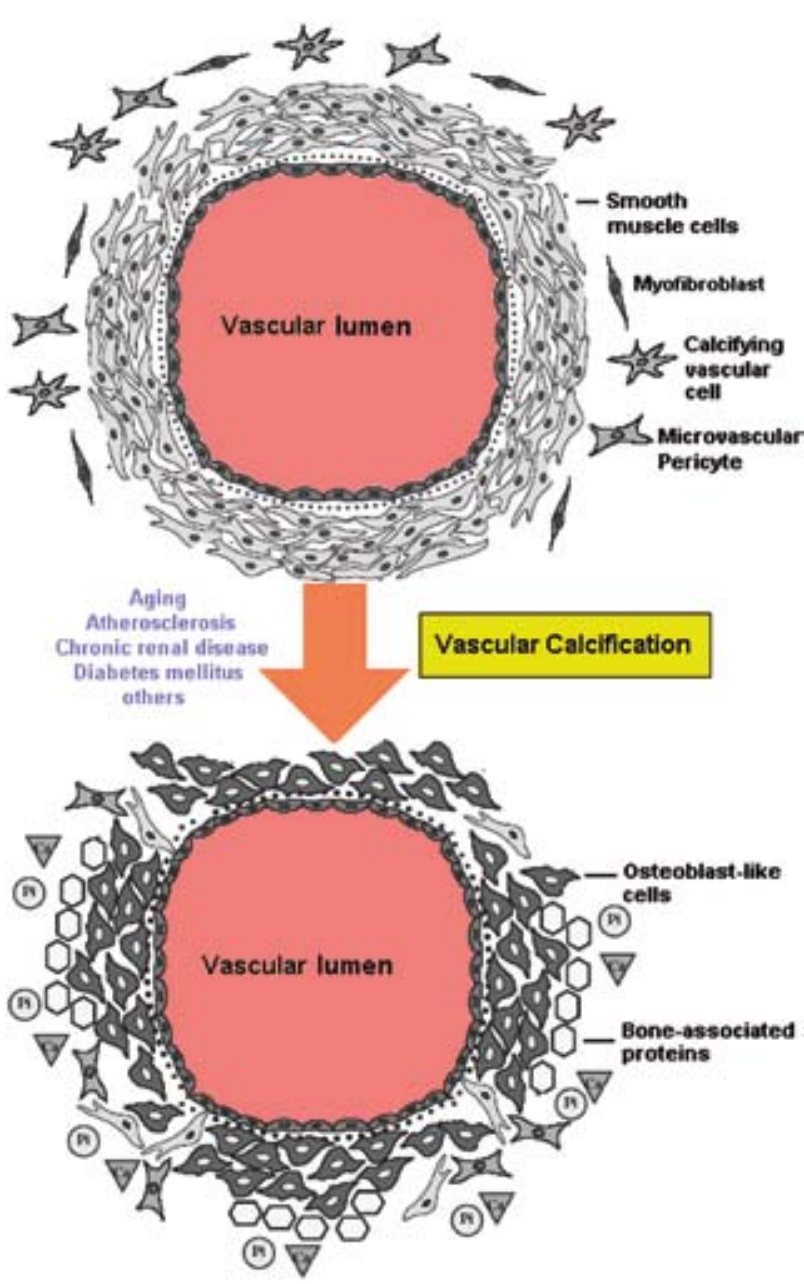

Figure 2. Hypothetical mechanisms of vascular calcification.

The final step might be the subsequent mineralization of the extracellular matrix. ${ }^{2}$

Vascular SMCs and osteoblasts are derived from similar precursor mesenchymal cells. Core binding factor $\alpha-1(\mathrm{Cbf} \alpha 1)$ is considered the transcriptional activator in the differentiation of mesenchymal cell to the osteoblast phenotype, as implied by the observation of deficient bone mineralization in mice lacking this factor. ${ }^{74}$ Moe et al ${ }^{75}$ characteristically describe the expression of Cbf $\alpha 1$, confirmed by in situ hybridization, immunostaining and RT-PCR in both the media and the intima in pathological specimens of calcified arteries from renal transplant patients, whereas minimal expression was observed in non-calcified vessels. These findings are consistent with experimental work by Tyson et al, ${ }^{76}$ who also describe the expression of Cbf $\alpha 1$, as well as other bone metabolism associated proteins, in calcified, but not in non-calcified atherosclerotic lesions from patients with normal renal function. These data imply that the expression of Cbf $\alpha 1$ is associated with the dedifferentiation of vascular SMCs into osteoblast resembling phenotypes, without clarifying whether the expression of this particular factor is a precondition or a marker of the dedifferentiation..$^{20}$

Experimental data have shown that vascular calcification is accelerated by uraemic toxins, present in the serum of patients undergoing haemodialysis, presumably through induced expression of core binding factor $\alpha-1$, resulting in vascular SMCs differentiation. This process is only partly attributed to hyperphosphataemia, since several other factors might be involved as well in the cellular phenotype alterations. Protein kinase A and bone morphogenetic protein-2 (BMP-2) have been identified as such factors. BMP-2 is a potent inducer of bone differentiation of mesenchymal stem cells $\mathrm{s}^{77}$ and is expressed in calcified human arteries as well as calcifying vascular SMCs. ${ }^{65}$

\section{MAIN CALCIFICATION PROMOTERS}

Phosphate and sodium dependent phosphate co-transporter seem to play a very important role in vascular SMCs mineralization (Figure 3). In patients suffering from ESRD, hyperphosphataemia is an almost 'typical' finding. Observational studies have revealed a somewhat increased frequency of vascular calcifications following the occurrence of hypercalcaemia, hyperphosphataemia or even everyday use

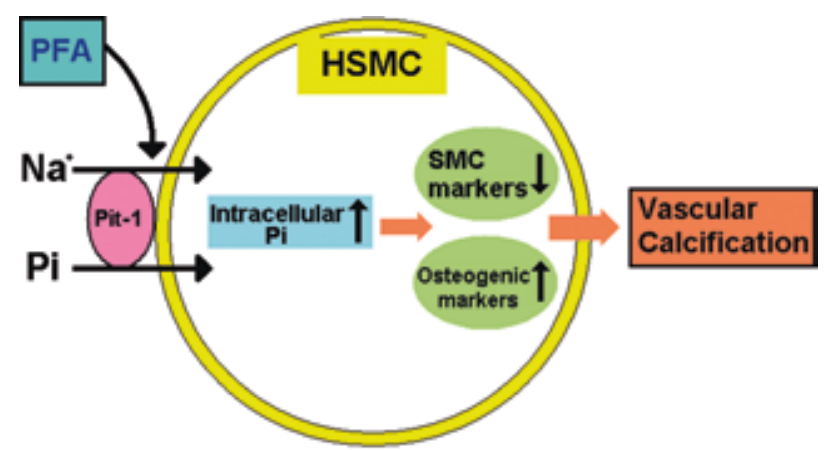

Figure 3. Phosphorus and Pit-1 sodium co-transporter as promoters of vascular calcification. HSMC: Human smooth muscle cells culture. PFA: Plasma Fetuin-A, Pit-1: Sodium dependent phosphate co-transporter 1. 
of calcium based phosphate binders, known as CaBPBs. ${ }^{78,79}$ Raggy et al have shown that there is a very strong correlation between phosphate levels and the magnitude of vascular calcifications, ${ }^{1}$ while a strong relation exists between hyperphosphataemia and high mortality among patients undergoing haemodialysis. ${ }^{80}$ In vitro experiments also support the view that a lot of 'non-traditional' cardiovascular risk factors, such as transforming growth factor (TGF)- $\beta$, uraemia, and high phosphate levels, are involved in vascular calcification and atherosclerosis. ${ }^{81}$ Specifically, elevation of phosphate levels in vascular SMCs cultures is accompanied by increased calcium deposits. ${ }^{67}$ In addition, a series of phenotypic changes were observed in the aforementioned cultured cells,${ }^{82}$ including the loss of SMCs markers (e.g. a-actin) and adoption of osteogenetic profile, such as the appearance of osteocalcin, core binding factor-1 (cbf-1), or even the formation of collagen-rich extracellular matrix. ${ }^{69,83}$

The previously described vascular SMCs calcification and phenotypic cell change is experimentally connected with the activity of sodium dependent phosphate co-transporter. As long as the presence of $\mathrm{NaCl}$ is assured, the intra-cellular increase of phosphate level proves to be time-dependent.

Three different types of co-transporters have been identified till now, types I, II, III. Type III presents two discrete subtypes, Pit-1 and Pit-2. In human vascular SMCs, co-transporter Pit-1 is mainly expressed. ${ }^{47}$ Apatite formation by SMCs, as a response to increased phosphate levels, is fully inhibited by phosphonoformic acid (PFA), a sodium dependent phosphorus co-transporter inhibitor, a finding supporting the notion that vascular calcification is an active rather than passive cellular process. ${ }^{83,84}$

Moreover, other experimental works describe the dose-dependent increment of intracellular phosphate levels through higher expression of the Pit-1 gene. Time-dependent induction of human vascular SMCs mineralization under the atherogenic effect of platelet-derived growth factor (PDGF) is also seen, even when serum phosphate levels are normal. The aforementioned elements clearly indicate that atherogenic factors (traditional or not) possibly predispose to vascular calcification by affecting the transmembrane phosphate transport process. ${ }^{2}$ Additionally, acceleration of media calcification is thought to be promoted through the systemic use of CaBPBs or even the use of high calcium concentration solutions during haemodialysis. ${ }^{85}$

Similarly, inflammation, a basic component of atheromatosis, predisposes to vascular calcifications in ESRD ${ }^{86}$ Inflammation markers, such as C-reactive protein (CRP), are elevated in chronic kidney disease.${ }^{87}$ This inflammatory 'stress' is followed by a decrease in mineralization inhibitors levels as discussed below.

\section{MAIN CALCIFICATION INHIBITORS}

Electrolyte disorders such as hyperphosphataemia and hypercalcaemia seem to contribute positively to the development of extraosseus calcification in patients with ESRD, while specific protein-calcium regulators may act as local or systemic calcification inhibitors. Under normal conditions, serum calcium and phosphate concentrations exceed the solubility limits of plasma, which means that plasma is supersaturated for the above minerals. The fact that normally no extraosseus calcification occurs implies the existence of active inhibitory mechanisms of mineral precipitation. ${ }^{88}$ Recent findings suggest that a delicate equilibrium between calcification promoters, like serum phosphates, and inhibitors, such as fetuin-A and matrix protein MGP, determines whether vascular wall calcification will be observed in chronic uraemic conditions (Figure 4). ${ }^{2}$

\section{FETUIN-A}

An important systemic extraosseus mineralization inhibitor thus far identified is fetuin-A or a2-HS-glycoprotein. Fetuin-A is abundant in the plasma, where it forms a complex with matrix protein Gla (MGP).$^{30}$ It is produced mainly in the liver of human adults, being a soluble TGF- $\beta$ antagonist, while it interacts with insulin receptor tyrosine kinase.$^{60,89,90}$ Fetuin-A inhibits the de novo formation and precipitation of basic calcium phosphate, which is considered to be the apatite precursor, but it does not dissolve it once it has been formed. Consequentially, fetuin-A can inhibit calcification in circulation without affecting the normal bone mineralization. ${ }^{91}$ In fetuin-A knock-out mice, extended extraosseous calcification was ob- 


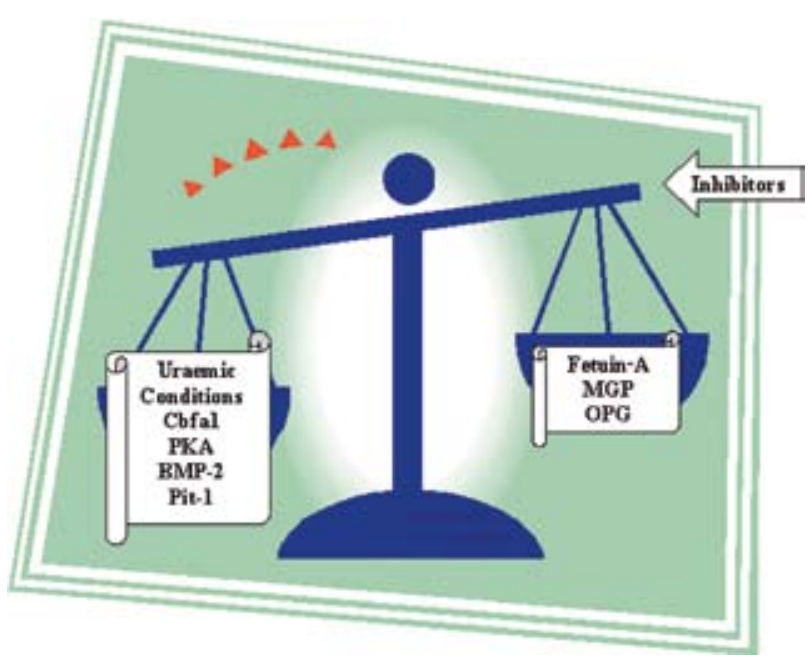

Figure 4. Main molecular promoters and inhibitors involved in coronary artery calcification in end stage renal disease. Abbreviations: Cbfa1: core binding factor a1, PKA: Protein Kinase A, BMP-2: Bone Morphogenetic Protein-2, Pit-1: Sodium dependent phosphate co-transporter-1, MGP: Matrix Gla Protein, OPG: Osteoprotegerin.

served under hypercalcaemic conditions. ${ }^{90}$ In patients with ESRD serum fetuin-A levels are significantly reduced. ${ }^{84,92}$ Additionally, serum of patients with chronic kidney disease has impaired ex vivo capacity to inhibit hydroxyapatite precipitation, which can be normalized by addition of pure fetuin-A. Fetuin-A concentration in systemic circulation is reduced during inflammation in patients under haemodialysis, while it correlates inversely to CRP levels, meaning that it is a negative acute phase protein. ${ }^{84}$ Moreover, low levels of fetuin-A are related to increased cardiovascular mortality. ${ }^{84,88}$ In patients under haemodialysis, serum fetuin-A levels inversely correlate with the extent and grade of coronary calcification, measured by means of spiral computed tomography (CT) scan. However, it should be noted that in some patients under haemodialysis, fetuin-A levels are not reduced. Possibly, there may be a relative fetuin-A deficiency in most but not in all dialysis patients. ${ }^{20}$

\section{MATRIX Gla PROTEIN (MGP)}

MGP is a protein with a molecular weight of about 10 Kdal containing $5 \gamma$ carboxyglutamic acid (GLA) residues which are responsible for its calcium binding capacity. ${ }^{93}$ It is normally expressed in cartilages, in endothelial and in vascular SMCs, while its gene expression is regulated by various growth factors and hormones. ${ }^{2}$ Additionally, MGP inhibits the activity of bone morphogenetic protein BMP-2, which is involved in bone transformation of vascular SMCs. In experiments using MGP knock-out mice, severe arterial wall and cartilage calcifications were observed. ${ }^{63}$ In patients with coronary heart disease and vascular wall calcifications, serum MGP levels were significantly reduced in comparison with patients without calcifications. ${ }^{94}$ Vitamin K deficiency as a result of either malnutrition or systemic use of anticoagulants such as warfarin may possibly lead to vascular wall calcification.$^{88}$ Regardless of the mechanism involved, MGP constitutes an important inhibitor of vascular calcification and mineral precipitation, suggesting that it serves as a major vascular and bone homeostasis modulator.

\section{OSTEOPROTEGERIN (OPG)}

Osteoprotegerin, a member of the tumour necrosis factor (TNF) receptor family, has been identified as a regulator of bone resorption mainly through an effect on osteoclast activity. ${ }^{2}$ OPG is produced by many different tissues, including the cardiovascular system, lung, kidney and immune system. OPG immunoreactivity was demonstrated not only in the non-diseased vessel wall but also in early atherosclerotic lesions. In advanced calcified lesions, OPG was present around the calcified area. ${ }^{95}$ It has been shown that OPG-deficient mice develop severe osteoporosis and medial artery calcification and that the development of osteoporosis and arterial calcification was completely prevented by restoration of the gene ${ }^{64}$ suggesting that OPG may function as a local inhibitor of vascular calcification. According to experimental results, it would be expected that OPG deficiency is connected with high risk for extraosseous mineralization. On the other hand, OPG levels in patients undergoing dialysis are found elevated compared to healthy volunteers. ${ }^{96}$ The interpretation of this paradox is not satisfactory. It remains unclear whether OPG is a potential cardiovascular marker or a compensatory mechanism eliminating the effects of atherogenesis and extraosseous calcification. It has also been demonstrated that serum OPG levels are correlated with the severity of coronary artery disease and constitute an independent risk factor of 
the progression of atherosclerosis..$^{97,98}$ The mechanism, however, through which OPG levels are elevated in patients with advanced coronary calcification, remains uncertain. A possible scenario is that OPG is involved in the development of vascular calcification through inhibition of TRAIL (TNF Related Apoptosis-Inducing Ligand) induced vascular cell apoptosis. ${ }^{2}$

\section{CONCLUDING REMARKS AND PERSPECTIVES}

From the aforementioned data it becomes evident that coronary calcification in ESRD is not a passive phenomenon due to calcium and phosphate supersaturated serum, but rather an active process involving cell differentiation and a delicate balance between calcification promoters and inhibitors. The specific role of endocrine disorders that accompany renal failure, such as hyperparathyroidism, must be clarified as well as the molecular basis of their participation in vascular calcification.

It is also known that atherosclerosis in chronic kidney disease is not only the result of 'traditional' risk factors such as those revealed by the Framingham Study but also of the unavoidable consequences of uraemic conditions.

All the therapeutic interventions thus far applied address parts of the phenomena described above without targeting the entire endocrine-metabolic derangement. In fact, there are many missing pieces in our understanding of how uraemia is 'translated' by the cells and how different cellular functions, including differentiation, proliferation and apoptosis, promote atherosclerosis and vascular calcification. The concept of a common model which can combine different aspects such as inflammation, dyslipidemia, uraemic toxicity and electrolyte disorders seems still a long way off. Such a model could possibly lead to a deeper understanding of the pathophysiology of vascular calcification and probably to the introduction of an intervention based on etiopathogenesis.

\section{REFERENCES}

1. Raggi P, Boulay A, Chasan-Taber S, et al, 2002 Cardiac calcification in adult hemodialysis patients. A link between end-stage renal disease and cardiovascular disease? J Am Coll Cardiol 39: 695-701.

2. Jono S, Shioi A, Ikari Y, Nishizawa Y, 2006 Vascular calcification in chronic kidney disease. J Bone Miner Metab 24: 176-181.

3. Meema HE, Oreopoulol DG, De Veber GA, 1976 Arterial calcification in severe chronic renal disease and their relationship to dialysis treatment, renal transplant and parathyroidectomy. Radiology 121: 315-321.

4. Parfitt AM, 1969 Soft-tissue calcification in uremia. Arch Intern Med 124: 544-556

5. Kuzela DC, Huffer WE, Conger JD, Winter SD, Hammond WS, 1977 Soft tissue calcification in chronic dialysis patients. Am J Pathol 86: 403-424.

6. Foley RN, Parfrey PS, Sarnak MJ, 1998 Clinical epidemiology of cardiovascular disease in chronic renal disease. Am J Kidney Dis 32: S112-S119.

7. Collins AJ, Li S, Ma JZ, Herzog C, 2001 Cardiovascular disease in end-stage renal disease patients. Am J Kidney Dis 38: Suppl 1: 26-29.

8. Levin A, 2003 Clinical Epidemiology of cardiovascular disease in Chronic kidney disease prior to dialysis. Seminars in Dialysis 16: 101-105.

9. Levin A, Djurdjev O, Barrett B, et al, 2001 Cardiovascular disease in patients with chronic kidney disease: getting to the heart of the matter. Am J Kidney Dis 38: 13981407.

10. US Renal Data System, 1999 USRDS 1999 annual data report. Am J Kidney Dis 34: Suppl 1: 87-94.

11. Sarnak MJ, 2003 Cardiovascular complications in chronic kidney disease. Am J Kidney Dis 41: Suppl: 11-17.

12. London GM, 2003 Cardiovascular disease in chronic renal failure: pathophysiologic aspects. Semin Dial 16: 85-94.

13. Sarnak MJ, Levey AS, Schoolwerth AC, et al, 2003 Kidney disease as a risk factor for development of cardiovascular disease: a statement from the American Heart Association Councils on Kidney in Cardiovascular Disease, High Blood Pressure Research, Clinical Cardiology, and Epidemiology and Prevention. Circulation 108: 2154-2169.

14. Tomiyama C, Higa A, Dalboni MA, et al, 2006 The impact of traditional and non-traditional risk factors on coronary calcification in pre-dialysis patients. Nephrol Dial Transplant 21: 2464-2471.

15. Muntner P, He J, Astor BC, Folsom AR, Coresh J, 2005 Traditional and Nontraditional Risk Factors Predict Coronary Heart Disease in Chronic Kidney Disease: Results from the Atherosclerosis Risk in Communities Study. J Am Soc Nephrol 16: 529-538.

16. Cheung AK, Sarnak MJ, Yan G, et al, 2000 Atherosclerotic cardiovascular disease risks in chronic hemodialysis patients. Kidney Int. 58: 353-362.

17. Prichard S, 2003 Risk factors for coronary artery disease in patients with renal failure. Am J Med Sci 325: 209-213.

18. Longenecker JC, Coresh J, Powe NR, et al, 2002 Traditional cardiovascular disease risk factors in dialysis patients compared with the general population: the CHOICE Study. J Am Soc Nephrol 13: 1918-1927.

19. Sarnak MJ, Coronado BE, Greene T, et al, 2002 Cardio- 
vascular disease risk factors in chronic renal insufficiency. Clin Nephrol 57: 327-335.

20. Moe SM, Chen NX, 2004 Pathophysiology of Vascular Calcification in Chronic Kidney Disease. Cir Res 95: 560-567.

21. London GM, Guerin AP, Marchais SJ, et al, 2003 Arterial media calcification in end-stage renal disease: impact on all-cause and cardiovascular mortality. Nephrol Dial Transplant 18: 1731-1740.

22. Silberberg JS, Barre PE, Prichard SS, Sniderman AD, 1989 Impact of left ventricular hypertrophy on survival in end-stage renal disease. Kidney Int 36: 286-290.

23. Speer MY, Giachelli CM, 2004 Regulation of cardiovascular calcification. Cardiovascular Pathology 13: 63-70.

24. London GM, 2003 Cardiovascular Calcifications in Uremic Patients: Clinical Impact on Cardiovascular Function. J Am Soc Nephrol 14: S305-S309.

25. Blacher J, Demuth K, Guerin AP, Safar ME, Moatti N, London GM, 1998 Influence of biochemical alterations on arterial stiffness in patients with end-stage renal disease. Arterioscler Thromb Vasc Biol 18: 535-541.

26. Wilson PW, Kauppila LI, O’Donnell CJ, et al, 2001 Abdominal aortic calcific deposits are an important predictor of vascular morbidity and mortality. Circulation 103: 1529-1534.

27. Blacher J, Guerin AP, Pannier B, Marchais SJ, London GM, 2001 Arterial Calcifications, Arterial Stiffness, and Cardiovascular Risk in End-Stage Renal Disease. Hypertension 38: 938-942.

28. He ZX, Hedrick TD, Pratt CM, et al, 2000 Severity of coronary artery calcification by electron beam computed tomography predicts silent myocardial ischemia. Circulation 101: 244-251.

29. Sangiorgi G, Rumberger JA, Severson A, et al, 1998 Arterial calcification and not lumen stenosis is highly correlated with atherosclerotic plaque burden in humans: a histologic study of 723 coronary artery segments using non-decalcifying methodology: electron beam computed tomography and coronary artery disease: scanning for coronary artery calcification. J Am Coll Cardiol 31: 126133.

30. Mautner SL, Mautner GC, Froehlich J, et al, 1994 Coronary artery disease: prediction with in vitro electron beam CT. Radiology 192: 625-630.

31. Rumberger JA, Simons DB, Fitzpatrick LA, Sheedy PF, Schwartz RS, 1995 Coronary artery calcium area by electron-beam computed tomography and coronary atherosclerotic plaque area. A histopathologic correlative study. Circulation 92: 2157-2162.

32. Puentes G, Detrano R, Tang W, et al, 1995 Estimation of coronary calcium mass using electron beam computed tomography: a promising approach for predicting coronary events? Circulation 92: I313.

33. Arad Y, Spadaro LA, Goodman K, Newstein D, Guerci AD, 2000 Prediction of coronary events with electron beam computed tomography. J Am Coll Cardiol 36:
1253-1260.

34. Berman DS, Hachamovitch R, Shaw LJ, 2006 Roles of Nuclear Cardiology, Cardiac Computed Tomography, and Cardiac Magnetic Resonance: Assessment of Patients with Suspected Coronary Artery Disease. J Nucl 47: 74-82.

35. Taylor AJ, Merz CN, Udelson JE, 2003 34th Bethesda Conference: executive summary - can atherosclerosis imaging techniques improve the detection of patients at risk for ischemic heart disease? J Am Coll Cardiol 41: 1860-1862.

36. Pundziute G, Schuijf JD, Jukema W, et al, 2007 Prognostic Value of Multislice Computed Tomography Coronary Angiography in Patients With Known or Suspected Coronary Artery Disease. JACC 49: 62-70.

37. O'Rourke RA, Brundage BH, Froelicher VF, et al, 2000 American College of Cardiology/American Heart Association Expert Consensus Document on electron-beam computed tomography for the diagnosis and prognosis of coronary artery disease. J Am Coll Cardiol 36: 326340.

38. Hujairi NM, Afzali B, Goldsmith DJ, 2004 Cardiac calcification in renal patients: what we do and don't know. Am J Kidney Dis 43: 234-243.

39. Goodman WG, Goldin J, Kuizon BD, et al, 2000 Coronary-artery calcification in young adults with end-stage renal disease who are undergoing dialysis. N Engl J Med 342: 1478-1483.

40. Oh J, Wunsch R, Turzer M, et al, 2002 Advanced coronary and carotid arteriopathy in young adults with childhoodonset chronic renal failure. Circulation 106: 100-105.

41. Braun J, Oldendorf M, Moshage W, et al, 1996 Electron beam computed tomography in the evaluation of cardiac calcification in chronic dialysis patients. Am J Kidney Dis 27: 394-401.

42. Moe SM, O'Neill KD, Fineberg N, et al, 2003 Assessment of vascular calcification in ESRD patients using spiral CT. Nephrol Dial Transplant 18: 1152-1158.

43. Moe SM, O’Neill KD, Resterova M, et al, 2004 Natural history of vascular calcification in dialysis and transplant patients. Nephrol Dial Transplant 19: 2387-2393.

44. Vatikutti R, Towler DA, 2004 Osteogenic regulation of vascular calcification: an early perspective. Am J Physiol Endocrinol Metab 286: E686-E696.

45. Floege J, Ketteler M, 2004 Vascular calcification in patients with end-stage renal disease. Nephrol Dial Transplant 19: Suppl 5: v59-v66.

46. Kalandar-Zadeh K, Block G, Humphreys MH, Kopple JD, 2003 Reverse epidemioliogy of cardiovascular risk factors in maintenance dialysis patients. Kidney Int 63: 793-808.

47. London GM, 2000 Alterations of arterial function in end-stage renal disease. Nephron 84: 111-118.

48. Proudfoot D, Shanahan CM, 2001 Biology of calcification in vascular cells: intima versus media. Herz 26: 245-251. 
49. Moe SM, O’Neill KM, Dual D, et al, 2002 Medial artery calcification in ESRD patients is associated with deposition of bone matrix proteins. Kidney Int 61: 638-647.

50. Morena M, Canaud B, Terrier N, Canaud L, Cristol JP, 2007 Oxidative stress complex syndrome: The dark side of the malnutrition-inflammation complex syndrome. Hemodial Int 11:Suppl 1: 32-38.

51. Yao Q, Axelsson J, Stenfinkel P, Lindholm B 2004 Chronic systemic inflammation in dialysis patients: an update on causes and consequences. ASAIO J 50: lii-lvii.

52. O'Rourke RA, Brundage BH, Froelicher VF, et al, 2000 American College of Cardiology/American Heart Association Expert Consensus document on electron-beam computed tomography for the diagnosis and prognosis of coronary artery disease. Circulation 102: 126-140.

53. Stanford W, Thompson BH, Burns TL, Heery SD, Burr MC, 2004 Coronary artery calcium quantification at multi-detector row helical CT versus electron-beam CT. Radiology 230: 397-402.

54. Wang AY, Wang M, Woo J, et al, 2003 Cardiac valve calcification as an important predictor of all-cause mortality and cardiovascular mortality in long-term peritoneal dialysis patients: a prospective study. J Am Soc Nephrol 14: 159-168.

55. Guerin AP, London GM, Marchais SJ, Metivier F, 2000 Arterial stiffening and vascular calcifications in end-stage renal disease. Nephrol Dial Transplant 15: 1014-1021.

56. Ahmed S, O’Neill KD, Hood AF, Moe SM, 2001 Calciphylaxis is associated with hyperphosphatemia and increased osteopontin expression by vascular smooth muscle cells. Am J Kidney Dis 37: 1267-1276.

57. Blacher J, Guerin AP, Pannier P, London GM, 2001 Arterial calcification, arterial stiffness and cardiovascular risk in end-stage renal disease. Hypertension 38: 938-942.

58. Stompor T, Pasowicz M, Sullowicz W, et al, 2003 An association between coronary artery calcification score, lipid profile and selected markers of chronic inflammation in ESRD patients treated with peritoneal dialysis. Am J Kidney Dis 41: 203-211.

59. Kronenberg F, Mundler M, Langle M, Neyer U, 2003 Prevalence and progression of peripheral arterial calcifications in patients with ESRD. Am J Kidney Dis 41: 140-148.

60. Schafer C, Heiss A, Schwarz A, et al, 2003 The serum protein alpha 2-Heremans-Schmid glycoprotein/fetuin-A is a systemically acting inhibitor of ectopic calcification. J Clin Invest 112: 357-366.

61. Moe SM, Chen XN, O'Neill KD, et al, 2003 Fetuin-A and matrix gla protein (MGP) are important inhibitors of vascular calcification in CKD. J Am Soc Nephrol 14: 692.

62. Tamashiro M, Iseki K, Sunagava O, et al, 2001 Significant association between the progression of coronary artery calcification and dyslipidemia in patients on chronic haemodialysis. Am J Kidney Dis 38: 64-69.

63. Luo G, Ducy P, McKee MD, et al, 1997 Spontaneous calcification of arteries and cartilage in mice lacking matrix GLA protein. Nature 386: 78-81.

64. Bucay N, Sarosi I, Dunstan CR, et al, 1998 Osteoprotegerindeficient mice develop early onset osteoporosis and arterial calcification. Genes Devel 12: 1260-1268.

65. Bostrom K, Watson KE, Horn S, Wortham C, Herman IM, Demer LL, 1993 Bone morphogenetic protein expression in human atherosclerotic lesions. J Clin Invest 91: 1800-1809.

66. Shioi A, Nishizawa Y, Jono S, Koyama H, Hosoi M, Morii H, 1995 Betaglycerophosphate accelerates calcification in cultured bovine vascular smooth muscle cells. Arterioscler Thromb Vasc Biol 15: 2003-2009.

67. Jono S, McKee MD, Murry CE, et al, 2000 Phosphate regulation of vascular smooth muscle cell calcification. Circ Res 87: E10-17

68. Jono S, Nishizawa Y, Shioi A, Morii H, 1998 1,25-Dihydroxyvitamin D3 increases in vitro vascular calcification by modulating secretion of endogenous parathyroid hormone-related peptide. Circulation 98: 1302-1306.

69. Chen NX, O’Neill KD, Duan D, Moe SM, 2002 Phosphorus and uremic serum up-regulate osteopontin expression in vascular smooth muscle cells. Kidney Int 62: 1724-1731.

70. Parhami F, Basseri B, Hwang J, Tintut Y, Demer LL, 2002 High-density lipoprotein regulates calcification of vascular cells. Circ Res 91: 570-576.

71. Proudfoot D, Davies JD, Skepper JN, Weissberg PL, Shanahan CM, 2002 Acetylated low-density lipoprotein stimulates human vascular smooth muscle cell calcification by promoting osteoblastic differentiation and inhibiting phagocytosis. Circulation 106: 3044-3050.

72. Li J, Chai S, Tang C, Du J, 2003 Homocysteine potentiates calcification of cultured rat aortic smooth muscle cells. Life Sci 74: 451-461.

73. Jono S, Nishizawa Y, Shioi A, Morii H, 1997 Parathyroid hormone-related peptide as a local regulator of vascular calcification. Its inhibitory action on in vitro calcification by bovine vascular smooth muscle cells. Arterioscl Thromb Vasc Biol 17: 1135-1142.

74. Ducy P, Zhang R, Geoffroy V, Ridall AL, Karsenty G, 1997 Osf2/Cbfa1: a transcriptional activator of osteoblast differentiation. Cell 89: 747-754.

75. Moe SM, Duan D, Doehle BP, O’Neill KD, Chen NX, 2003 Uremia induces the osteoblast differentiation factor Cbfa1 in human blood vessels. Kidney Int 63: 10031011.

76. Tyson KL, Reynolds JL, McNair R, Zhang Q, Weissberg PL, Shanahan CM, 2003 Osteo/Chondrocytic transcription factors and their target genes exhibit distinct patterns of expression in human arterial calcification. Arterioscler Thromb Vasc Biol 23: 489-494.

77. Bostrom K, Tsao D, Shen S, Wang Y, Demer LL, 2001 Matrix gla protein modulates differentiation induced by bone morphogenetic protein-2 in c $3 \mathrm{~h} 10 \mathrm{t} 1 / 2$ cells. J Biol Chem 276: 14044-14052. 
78. Block GA, Port FK, 2000 Re-evaluation of risks associated with hyperphosphatemia and hyperparathyroidism in dialysis patients: recommendations for a change in management. Am J Kidney Dis 35: 1236-1237.

79. Goodman WG, London G, Amann K, et al, 2004 Vascular calcification in chronic kidney disease. Am J Kidney Dis 43: $572-579$

80. Block GA, Hulbert-Shearon TE, Levin NW, Port FK, 1998 Association of serum phosphorus and calcium phosphate product with mortality risk in chronic hemodialysis patients: a national study. Am J Kidney Dis 31: 607-617.

81. Cozzolino M, Dusso AS, Slatopolsky E, 2001 Role of calcium- phosphate product and bone-associated proteins on vascular calcification in renal failure. J Am Soc Nephrol 12: 2511-2516.

82. Steitz SA, Speer MY, Curinga G, et al, 2001 Smooth muscle cell phenotypic transition associated with calcification: upregulation of Cbfa1 and downregulation of smooth muscle lineage markers. Circ Res 89: 1147-1154.

83. Giachelli SM, Jono S, Mori K, Morii H, 2001 Vascular calcification and inorganic phosphate. Am J Kidney Dis 38: S34-37.

84. Ketteler M, Bongartz P, Westenfeld R, et al, 2003 Association of low fetuin-A (AHSG) concentrations in serum with cardiovascular mortality in patients on dialysis: a cross-sectional study. Lancet 361: 827-833.

85. Raggi P, 2002 Effects of excess calcium load on the cardiovascular system measured with electron beam tomography in end-stage renal disease. Nephrol Dial Transplant 17: 332-335.

86. Dellegrottaglie S, Sanz J, Rajagopalan S, 2006 Vascular Calcification in Patients with Chronic Kidney Disease. Blood Purif 24: 56-62.

87. Zimmermann J, Herrlinger S, Pruy A, Metzger T, Wanner C, 1999 Inflammation enhances cardiovascular risk and mortality in hemodialysis patients. Kidney Int 55: 648-658.

88. Ketteler M, Westenfeld R, Schlieper G, Brandenburg $\mathrm{V}, 2005$ Pathogenesis of vascular calcification in dialysis patients. Clin Exp Nephrol 9: 265-270.

89. Ketteler M, Wanner C, Metzger T, et al, 2003 Deficiencies of calcium-regulatory proteins in dialysis patients: a novel concept of cardiovascular calcification in uremia. Kidney Int 84: Suppl: S84-87.

90. Westenfeld R, Smeets C, Schäfer C, et al, 2003 Extraosseous mRNA expression of bone associated proteins in uremic mice lacking Ahsg/fetuin-A. Nephrol Dial Transplant 18:Suppl 4: 593.

91. Schinke T, Amendt C, Trindl A, Poschke O, MullerEsterl W, Jahnen-Dechent W, 1996 The serum protein alpha2-HS glycoprotein/fetuin inhibits apatite formation in vitro and in mineralizing calvaria cells. A possible role in mineralization and calcium homeostasis. J Biol Chem 271: 20789-20796.

92. Mehrotra R, Westenfeld R, Christenson P, et al, 2005 Serum fetuin-A in nondialyzed patients with diabetic nephropathy: relationship with coronary artery calcification. Kidney Int 67: 1070-1077.

93. Price PA, Williamson MK, 1985 Primary structure of bovine matrix Gla protein, a new vitamin K-dependent bone protein. J Biol Chem 260: 14971-14975.

94. Jono S, Ikari Y, Vermeer C, et al, 2004 Matrix Gla protein is associated with coronary artery calcification as assessed by electron-beam computed tomography. Thromb Haemost 91: 790-794.

95. Dhore CR, Cleutjens JP, Lutgens E, et al, 2001 Differential expression of bone matrix regulatory proteins in human atherosclerotic plaques. Arterioscler Thromb Vasc Biol 21: 1998-2003.

96. Nitta K, Akiba T, Uchida K, et al, 2003 The progression of vascular calcification and serum osteoprotegerin levels in patients on long-term hemodialysis. Am J Kidney Dis 42: 303-309.

97. Jono S, Ikari Y, Shioi A, et al, 2002 Serum osteoprotegerin levels are associated with the presence and severity of coronary artery disease. Circulation 106: 1192-1194.

98. Kiechl S, Schett G, Wenning G, et al, 2004 Osteoprotegerin is a risk factor for progressive atherosclerosis and cardiovascular disease. Circulation 109: 2175-2180. 